\title{
PROPOSTA DE IMPLEMENTAÇÃO DE TREINAMENTO E DESENVOLVIMENTO: ESTUDO DE CASO NA EMPRESA NETUNO ENGENHARIA NAVAL
}

\section{ARTIGO ORIGINAL}

REMÉDIOS, Bruna Araújo dos ${ }^{1}$, SILVA, Taizes Clara Sales da², ALMEIRA, Victor da Silva ${ }^{3}$, ROBERTO, José Carlos Alves ${ }^{4}$

REMÉDIOS, Bruna Araújo Dos. Et al. Proposta de implementação de treinamento e desenvolvimento: estudo de caso na empresa netuno engenharia naval. Revista Científica Multidisciplinar Núcleo do Conhecimento. Ano. 06, Ed. 11, Vol. 10, pp. 182-201. Novembro 2021. ISSN: 2448-0959, Link de acesso: https://www.nucleodoconhecimento.com.br/administracao/implementacao-detreinamento, DOI: 10.32749/nucleodoconhecimento.com.br/administracao/implementacao-detreinamento

\section{RESUMO}

No parâmetro estratégico, todas as organizações necessitam passar por um processo de análise de seu ambiente, constatando oportunidades que possam ampliar seu mercado para um futuro brilhante. A capacitação e desenvolvimento de pessoas adentrou em quase todos os negócios, visando melhorias no atendimento ao cliente e buscando um diferencial competitivo. O presente artigo teve como propósito realizar um estudo de caso na empresa Netuno - Serviços de Consultoria e Engenharia Naval LTDA, que atua no ramo naval e pode ser considerada quanto

\footnotetext{
${ }^{1}$ Graduando do curso de Administração.

${ }^{2}$ Graduando do curso de Administração

${ }^{3}$ Coorientador. Mestrado em Engenharia de processos. Pós-graduando em Neuropsicopedagogia Institucional. Especialização em Gestão Estratégica de RH. Graduação em Administração e Pedagogia.

${ }^{4}$ Orientador. Mestrado profissional em Engenharia de Produção. Especialização em Gestão em Logística empresarial. Graduação em Administração com ênfase em Marketing.
}

$\mathrm{RC}: 101765$

Disponível em:

https://www.nucleodoconhecimento.com.br/administracao/implementacao-de- 
ao porte, uma microempresa, devido ao número de funcionários. Seu objetivo geral consistiu em definir como um programa bem estruturado de treinamento e desenvolvimento pode contribuir para o desenvolvimento da empresa por meio da qualidade do nível de serviço. $O$ artigo surgiu a partir da análise das áreas funcionais da empresa por meio do diagnóstico organizacional, onde identificou-se a área de marketing como sendo a área mais crítica da empresa, tendo em vista a ausência de consolidação da marca, o nível de serviço oferecido nos contratos e a capacidade técnica dos colaboradores. A pergunta norteadora pretende discutir, como a estruturação de um programa de capacitação de mão de obra pode subsidiar o crescimento da organização por meio da qualidade do atendimento do nível de serviço? Pois ao investir no capital intelectual de seus colaboradores, as corporações certamente terão maior produtividade e lucratividade. A metodologia empregada, quanto a natureza, foi de cunho qualitativo, quanto aos fins, deu-se por meio de um misto de pesquisas, incluindo a pesquisa exploratória, descritiva, explicativa e intervencionista, e quanto aos meios, foram realizadas pesquisas de campo e estudo de caso. A ferramenta interventiva utilizada foi o $5 \mathrm{~W} 2 \mathrm{H}$, para a introdução das ações interventivas, dando ênfase no mapeamento das atividades e na organização da LNT (levantamento de necessidades de treinamento) para cada colaborador dentro da organização. Espera-se que com a introdução das ações interventivas haja um melhor desempenho dos colaboradores referente a realização dos serviços prestados pela empresa de engenharia, tendo em vista a maior agilidade e um alto diferencial competitivo.

Palavras-chave: Treinamentos, Capacitação, Marketing, Organização.

\section{INTRODUÇÃO}

O presente artigo tem como propósito apresentar um estudo sobre os processos de treinamento e desenvolvimento de pessoas, baseado em diversos autores, detalhando como o treinamento dos colaboradores pode causar impactos positivos no crescimento da organização como um todo.

RC: 101765

Disponível em:

https://www.nucleodoconhecimento.com.br/administracao/implementacao-de- 
O objetivo geral do trabalho é definir como um programa bem estruturado de treinamento e desenvolvimento pode contribuir para o desenvolvimento da empresa por meio da qualidade do nível de serviço. Os objetivos específicos pretendem identificar possíveis contratempos advindos no atendimento aos clientes por parte dos colaboradores, avaliar diferentes tipos de treinamentos voltados para melhorias no setor operacional e administrativo e aplicar estratégias para o desenvolvimento dos serviços executados pela empresa.

Segundo Menezes (2019, p. 13), "para se realizar qualquer pesquisa, é necessário partir de uma questão que norteará todo o percurso investigativo a ser empreendido, por isso, tal problema pode ser apresentado em forma de pergunta." O conceito de treinamento está ligado diretamente com a preparação dos funcionários para atuarem em um mercado altamente competitivo, com isso, será apresentado no decorrer do trabalho a questão norteadora, sendo ela: como a estruturação de um programa de capacitação de mão de obra pode subsidiar o crescimento da organização por meio da qualidade do atendimento do nível de serviço?

Para evidenciar a eficácia deste procedimento, realizou-se um estudo de caso com a empresa Netuno Engenharia Naval, que atua no ramo naval. Foram utilizados métodos referente a pesquisa qualitativa aplicada que tem por objetivo gerar conhecimento e solucionar gargalos específicos dentro da organização, optou-se também por utilizar diferentes meios de pesquisa, como: pesquisa explicativa, descritiva e exploratória, a fim de obter resultados acerca da problematização apresentada neste artigo, que trata sobre como um programa de treinamento pode contribuir para o desenvolvimento da organização. Além disso, utilizou-se, ainda, dois recursos que foram imprescindíveis para coleta de dados, a pesquisa de campo e as entrevistas.

Os resultados esperados no final deste estudo é manifestar a importância do Treinamento e Desenvolvimento como mecanismo estratégico, propiciando 
resultados satisfatórios para a organização e fazendo com que os gestores invistam cada vez mais na sua equipe de colaboradores.

\section{FUNDAMENTAÇÃO TEÓRICA}

A fundamentação teórica ou referencial teórico pode ser vista como uma das etapas primordiais de um trabalho acadêmico, é de forma geral, uma análise de como outros autores abordam sobre o tema, ou seja, contribui de forma significativa para o desenvolvimento da pesquisa.

Quando bem executada, a fundamentação teórica concede um certo nível de confiabilidade e credibilidade ao trabalho. É importante também não se limitar a somente um autor, tendo em vista as diferentes perspectivas e pensamentos de diversos escritores.

\subsection{TREINAMENTO E DESENVOLVIMENTO DE PESSOAS}

O mundo globalizado sofre constantemente com mudanças e as organizações estão em busca, dia após dia, de melhorar o nível de atendimento para continuarem inseridas neste novo mercado altamente competitivo. Um bom programa de treinamento ajuda as empresas no quesito produtividade e ainda auxilia na redução de custos, gerando uma boa economia.

O termo treinamento refere-se a uma ação que visa capacitar pessoas a exercerem determinada atividade que, comumente, são executadas no dia a dia, com o objetivo de melhorar o desempenho do profissional.

Para Langhi (2019), a sobrevivência das organizações e o diferencial competitivo estão diretamente ligados com o treinamento e desenvolvimento dos colaboradores.

O processo de treinamento e desenvolvimento acrescenta na qualificação dos profissionais, propondo inúmeros benefícios não somente para o colaborador, mas 
para a organização como um todo, e pode ser visto como uma grande estratégia quando bem utilizado, gerando um diferencial competitivo.

O sucesso e crescimento de uma organização está associado à qualidade do atendimento, dos produtos e serviços ofertados por ela. A qualificação dos funcionários é indispensável e deve ser vista como um investimento que futuramente irá trazer vantagens para a empresa. Já a ausência de treinamento pode ser vista de forma negativa, resultando na insatisfação dos clientes.

Segundo Santos e Lopez (2021), o objetivo do treinamento e desenvolvimento é ajudar os funcionários a compreenderem as metas da organização, para contribuírem de forma significativa no desempenho da mesma.

Nos dias atuais, faz-se necessário estimular o constante desenvolvimento dos colaboradores de uma organização, por meio de um processo de aperfeiçoamento contínuo, realizado em longo prazo. Embora diferentes, esses dois métodos chamados treinamento e desenvolvimento são complementares um do outro e são meios de capacitação para os colaboradores da organização, visando sempre o crescimento profissional.

Como afirma Madruga (2018), ainda há muitas empresas que não valorizam o desenvolvimento por competências de seus colaboradores, por acreditarem que este não gera benefícios e que o custo é alto.

\subsubsection{AVALIAÇÃO E NECESSIDADE DE TREINAMENTO}

O levantamento de necessidades de treinamento pode ser visto como um dos pontos cruciais para um projeto de treinamento dentro de uma organização, seu objetivo principal é diagnosticar de forma preliminar quais são as dificuldades e oportunidades do grupo de colaboradores. Com a LNT é possível averiguar quais as deficiências de conhecimento e montar um esquema estratégico para melhorias contínuas.

RC: 101765

Disponível em:

https://www.nucleodoconhecimento.com.br/administracao/implementacao-detreinamento 
$\mathrm{Na}$ visão de Paes (2011), a LNT é o passo inicial para desenvolver de forma estratégica o desenvolvimento das organizações e nem sempre esta etapa é de fácil entendimento, pois faz-se necessário realizar inúmeros levantamentos e pesquisas.

O processo desta avaliação requer observações minuciosas para identificação de obstáculos no desempenho dos funcionários e da empresa. Pode-se destacar que o sucesso do programa de treinamento e desenvolvimento se dá por meio destas investigações.

Khoury (2015) apresenta o levantamento de necessidades de treinamento como uma etapa fundamental para aplicação de treinamentos bem executados, uma vez que a sua não realização pode resultar em soluções errôneas para a empresa.

O levantamento e a avaliação possui um papel valioso na preparação do treinamento, pois nesta etapa pode-se sugerir modificações, as quais trarão vantagens e bons resultados quando aplicadas (NOE, 2015)

Há diferentes métodos que podem ser utilizados como base no levantamento de necessidades de treinamentos, dos quais pode-se destacar:

Primeiro, a análise organizacional, que trata da averiguação de como os valores, a missão e a visão da organização estão sendo vistos pelos funcionários.

Segundo, a análise da estrutura que diz a respeito da função exercida.

Terceiro, a análise individual, que consiste no perfil profissional de cada colaborador, tratando das habilidades necessárias para o alcance de resultados.

\subsubsection{AS ETAPAS DO PROCESSO DE TREINAMENTO}

O treinamento é um processo que intensifica habilidades profissionais a fim de qualificar o desempenho das atividades que os colaboradores exercem dentro de uma organização. Regularmente, este processo é de curto prazo e com resultados

RC: 101765

Disponível em:

https:/www.nucleodoconhecimento.com.br/administracao/implementacao-detreinamento 
satisfatórios. Tais processos devem ser cautelosamente planejados de acordo com a realidade da empresa, todas as etapas do treinamento devem criar uma conexão de interesses para resultar em benefícios futuros.

Para Tonet et al. (2012), as empresas contemporâneas encaram uma realidade única, vista como a era do saber e conhecer, com um mercado exigente, que cobra habilidades diferentes das que eram cobradas na antiguidade.

Assim, pode-se destacar as 4 etapas do processo de treinamento:

Diagnóstico: é fundamental que esta primeira etapa seja executada, a fim de avaliar quais as necessidades e problemas enfrentados pela empresa e pelos colaboradores. Este estágio identifica preliminarmente tudo o que será apontado no treinamento. Uma forma simples de fazer este levantamento é através de pesquisas e coletas de dados.

Planejamento: Após o diagnóstico, esta etapa visa planejar o treinamento, levando em consideração de qual forma será executado, em que local, a data, a metodologia e o prazo. Desenvolver um bom planejamento é importante para o projeto ser bemsucedido. O ponto mais relevante deste estágio trata-se da estratégia que será desenvolvida e como será aplicada, detalhando assim, toda a estrutura do treinamento.

Implementação: a implementação ou execução refere-se à ação, ou seja, colocar em prática as etapas do treinamento. Faz-se necessário preparar o ambiente e desenvolver as tarefas juntamente com os colaboradores, é indispensável que todos os equipamentos estejam funcionando de forma adequada, a fim de garantir que todos os recursos estejam acessíveis.

Avaliação: a última etapa, após os treinamentos, equivale a avaliação do desempenho dos profissionais, verificando se todas as etapas foram cumpridas e 
checando se foi absorvido pelos colaboradores. Esta etapa é importante para manter a estratégia e verificar se as ações trouxeram os resultados esperados.

Segundo Paradela e Gomes (2021), não há ninguém que tenha adquirido tal nível de conhecimento que não precise mais, o processo de aprendizagem é infinito.

\subsubsection{TIPOS DE TREINAMENTO}

Atualmente os treinamentos são essenciais para o crescimento organizacional, sendo assim, tem como objetivo o desenvolvimento de pessoas visando o crescimento da organização.

Segundo Langhi (2019), o treinamento profissional compreende o ensino que capacita as pessoas para uma determinada função, sua finalidade é buscar acrescentar conhecimento para o desenvolvimento pessoal e organizacional.

Assim, para que os resultados sejam atingidos, é necessário realizar todas as etapas do treinamento, considerando que o treinamento muda o comportamento das pessoas, criando um ambiente satisfatório. $O$ aprendizado tem relação com o conhecimento, mas a base do treinamento não é o colaborador apenas entender, mas também colaborar com o crescimento e desenvolvimento da empresa, acrescentando vantagens estratégicas para a organização. Logo, é necessário o esforço da empresa para que seus colaboradores tragam bons resultados.

Noe (2015) aponta que a transmissão de conhecimento vai além das habituais aulas tradicionais, atualmente, as organizações decidiram inserir em seus treinamentos, tecnologias que facilitam a aprendizagem dos seus colaboradores e a busca por melhoria.

Por meio de treinamento de pessoas, as organizações seguem capacitando seus colaboradores a fim de gerar mudanças em suas funções, o objetivo é treiná-las para que realizem um trabalho com qualidade e competência.

RC: 101765

Disponível em:

https:/www.nucleodoconhecimento.com.br/administracao/implementacao-detreinamento 
Ademais, conforme Dessler, (2014), as organizações estão analisando o mercado, especulando quais funções estão sendo procuradas atualmente, com vista às necessidades futuras das empresas.

Segundo Ribeiro (2018), treinamentos trazem muitas vantagens para as empresas, pois diminui reclamações, possibilita a execução das atividades com excelência, motiva o colaborador e, consequentemente, melhora sua produtividade, colaborando com o crescimento organizacional.

\subsubsection{DESENVOLVIMENTO}

Muitas organizações focam na importância de qualificar seus colaboradores e investem em treinamentos que buscam o desenvolvimento de pessoas, levando-as a aprimorar seus conhecimentos e trazendo benefícios que agregam o crescimento organizacional. Diante disso, as empresas buscam melhoria contínua que venham atribuir novos conhecimentos para com seus funcionários.

Nesse cenário, o desenvolvimento das organizações está diretamente ligado à preparação de seus colaboradores com o desenvolvimento de competências específicas. As empresas investem em inovações que intervêm positivamente em seus colaboradores. Contudo, o processo de desenvolvimento requer que a gestão organizacional esteja alinhada em um só objetivo, o diferencial estratégico de sucesso.

Faz-se necessário destacar que o patrimônio de uma organização são exclusivamente as pessoas, afinal de contas são elas que apresentam ideias, estratégias, e produzem resultados. A performance de uma pessoa está diretamente relacionada ao seu desenvolvimento e potencial de aprendizagem, sendo assim, vale ressaltar que a era tecnológica vem tomando espaço no mercado, e é notório que as empresas estão se atualizando junto ao mercado moderno, o que requer cada vez mais conhecimento das pessoas.

RC: 101765

Disponível em:

https://www.nucleodoconhecimento.com.br/administracao/implementacao-detreinamento 
Portanto, os incentivos das organizações no desenvolvimento das pessoas possibilitam que seus colaboradores apresentem suas capacidades e que as empresas avaliem o potencial de cada integrante apresentado. Marras (2012) passou a avaliar o comportamento e desenvolvimento das pessoas em seu ambiente de trabalho, tendo como alguns dos critérios estabelecidos o foco e a determinação, pelos quais pode-se ver o que motivava as pessoas a desenvolverem melhorias no lugar de trabalho.

No entanto, para atingir um objetivo, as empresas precisam garantir os padrões de qualidade conforme esperado e o desenvolvimento profissional dos colaboradores, em particular das capacidades de inovar, tendo como foco as pessoas.

De acordo com Reichel (2008), toda organização possui pessoas com conhecimento incrível, sendo assim, é necessário que as empresas incentivem as pessoas a demonstrá-las, tirando barreiras que as impedem de mostrar suas capacidades.

\subsubsection{IMPORTÂNCIA E CONTRIBUIÇÕES DO TREINAMENTO PARA A MELHORIA NA QUALIDADE DO SERVIÇO NAS ORGANIZAÇÕES}

O aprendizado vai muito além do conhecimento básico, atualmente as organizações vêm buscando profissionais atualizados e com conhecimento diferenciado. Tendo em vista que a tecnologia está cada vez mais avançando no mercado de trabalho, as empresas têm aderido programas de treinamento e capacitação de seus colaboradores, com o propósito de alcançar objetivos futuros.

Segundo Noe (2015), a gestão de conhecimento compreende a ênfase de aprimorar o conhecimento e desenvolver o desempenho de uma organização, implantando ferramentas que enriquecem o aprendizado profissional. $O$ treinamento tem como foco o aprendizado das pessoas, visando o desenvolvimento de suas capacidades profissionais. Vale ressaltar, que o treinamento contribui na melhoria $e$ desenvolvimento dos colaboradores, cabendo a organização se esforçar para que os mesmos obtenham esse recurso.

RC: 101765

Disponível em:

https://www.nucleodoconhecimento.com.br/administracao/implementacao-de- 
Como afirma Cortella (2016), com intuito de que o colaborador dê resultados para a organização, faz-se necessário que o mesmo trabalhe de forma clara.

É importante frisar que o crescimento das tecnologias requer qualificação e capacidade intelectual. Um dos desafios mais enfrentados nas organizações é a promoção de qualidade nos serviços, fator este pelo qual todas as empresas estão competindo. Logo, considerando que o foco é atingir qualidade no mercado, os treinamentos são essenciais para o crescimento organizacional, visando a capacitação dos colaboradores, para que a empresa possa crescer com vantagens competitivas no mercado.

As habilidades exigidas nas empresas são cada vez mais exigentes. Comunicação, inteligência emocional, criatividade são especialidade exigidas atualmente. As empresas estão mudando, as pessoas estão se atualizando e, novas formas de relação entre estas estão surgindo. Assim, as instituições estão investindo diretamente em treinamentos para que seus colaboradores tenham bons resultados e possam aplicar em suas empresas. É importante salientar que a organização precisa fazer um investimento de tempo e dinheiro para que sejam feitos treinamentos, no entanto, com isso haverá uma perda de produção, uma vez que os colaboradores estarão em treinamento, não executando sua função. Porém, deve-se considerar que isso trará resultados para a empresa.

Por fim, sugere-se que seja feita uma avaliação, a fim de analisar se o treinamento deu resultados, pois será a partir destes que a organização verificará o retorno. É através das pessoas que as organizações conquistam resultados, e no cenário atual, o foco é gerar resultados de alta performance.

\section{MATERIAIS E MÉTODOS}

A metodologia trata-se de uma ciência que compreende um conjunto de técnicas e métodos que são utilizados para pesquisas, estudos e investigações. Desta maneira, 
este artigo recorreu-se a diferentes instrumentos para a obtenção de soluções e resultados para os gargalos encontrados na empresa Netuno Engenharia Naval.

\subsection{PROCEDIMENTOS METODOLÓGICOS}

De acordo com Zanella (2013, p. 19), "em ciências, método é a maneira, é a forma que o cientista escolhe para ampliar o conhecimento sobre determinado objeto, fato ou fenômeno."

Deste modo, esta pesquisa desenvolveu-se por meio de coleta de dados, informações, roteiros de entrevistas e análises; e ações interventivas eficazes para solucionar problemas operacionais e administrativos da empresa Netuno.

\subsubsection{QUANTO À NATUREZA}

De acordo com Aragão e Neta (2017, p. 29), "qualquer que seja o método é fundamental a elaboração de um projeto de pesquisa que nos oriente, a partir do seu escopo na escolha do método mais adequado para a investigação."

Segundo Pereira et al. (2018, p. 67 ), "os métodos qualitativos são aqueles nos quais é importante a interpretação por parte do pesquisador com suas opiniões sobre o fenômeno de estudo.

Quanto à natureza utilizada no projeto, optou-se pela aplicada e qualitativa, pois trata-se de um processo descritivo, de observação dos dados coletados, para aplicação prática, visando sanar problemas.

\subsubsection{QUANTO AOS FINS}

Segundo Lima e Pereira (2018, p. 111), "a pesquisa descritiva, como já diz seu nome, objetiva a descrição de determinada população ou fenômeno, podendo também estabelecer relações entre as variáveis.

RC: 101765

Disponível em:

https://www.nucleodoconhecimento.com.br/administracao/implementacao-detreinamento 
Cooper e Schindler (2016) definiram que a pesquisa exploratória é utilizada para descobrir fenômenos desconhecidos, para obtenção de informações que não haviam sido identificadas anteriormente.

Portanto, quanto aos fins, este estudo deu-se por um misto de pesquisas, incluindo a pesquisa exploratória, descritiva, explicativa e intervencionista, que foram aplicadas a fim de obter informações necessárias para construção deste estudo e para identificação de possíveis soluções voltadas aos problemas encontrados na empresa Netuno.

\subsubsection{QUANTO AOS MEIOS}

Yin (2015) afirma que a necessidade do estudo de caso surge a partir da busca por informações exatas sobre fenômenos sociais complexos, o qual permite um foco total no caso.

De acordo com Zambello et al. (2018, p. 65), "quando o processo de coleta de dados se dá no local de onde ele emerge, estamos diante daquilo que denominamos de pesquisa de campo."

Quanto aos meios, recorreu-se ao estudo de caso e à pesquisa de campo, tendo em vista o objetivo de adquirir informações e o aprofundamento nas questões da empresa. Desta forma, é oportuno destacar que a coleta de dados ocorreu, na maioria das vezes, de forma presencial, perante os sócios da mesma.

\subsection{CARACTERIZAÇÃO DA EMPRESA}

A Netuno é uma empresa do ramo de engenharia, que presta serviços de consultoria no âmbito naval, além de elaborar projetos para construções de embarcações e portos. Seu escritório fica localizado na Rua Bernardo Ramos, no 92, Centro, na cidade de Manaus. A empresa foi fundada no ano de 2011, pelo Sr. Alexandre, que hoje já não faz mais parte do grupo de colaboradores da mesma. Atualmente, a

RC: 101765

Disponível em:

https:/www.nucleodoconhecimento.com.br/administracao/implementacao-detreinamento 
Netuno é comandada por três sócios e engenheiros navais: Matheus, Paulo e Victor. A Netuno vem ganhando cada vez mais espaço no mercado naval, oferecendo serviços de qualidade e fechando contratos com grandes empresas e até mesmo realizando serviços para a Marinha do Brasil.

\section{RESULTADOS E DISCUSSÕES}

O Sistema de medição de desempenho avalia a eficiência dos serviços prestados por uma organização. Trata-se de um processo que é feito por meio de indicadores de desempenho nas mais variadas áreas da empresa.

Sendo assim, ainda que os indicadores de desempenho sejam capazes de apontar os problemas da empresa, estes não os resolvem, cabendo, portanto, aos gestores executarem a resolução destes (FRANCISCHINI e FRANCISCHINI, 2017).

Com base nas observações realizadas na empresa Netuno, identificou-se a importância desta avaliação para melhorar a produtividade dos colaboradores, tratando as áreas com menores índices, com vista ao alcance das metas e objetivos.

Gráfico 01: Medição de Desempenho

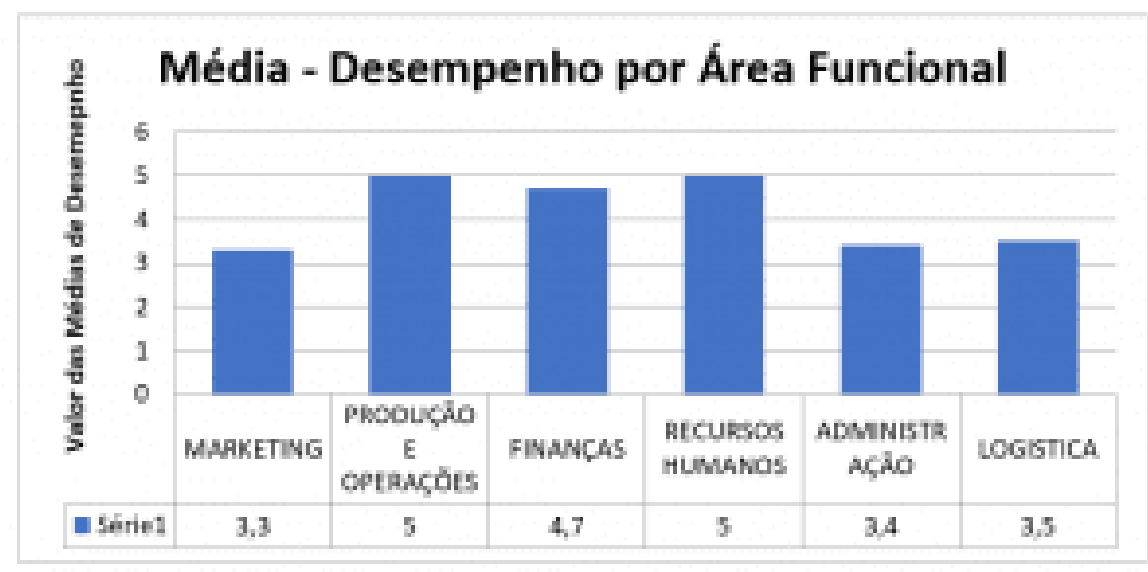

Fonte: Elaborado pelos autores, 2021.

RC: 101765

Disponível em:

https://www.nucleodoconhecimento.com.br/administracao/implementacao-detreinamento 
Diante dos dados expostos, observou-se que as áreas de melhor desempenho foram a de Produção e Operações e Recurso Humanos, as medianas foram as de Finanças, Logística e Administração, e a área com menor índice de desempenho foi o Marketing, assim, tendo que ser analisada com maior cautela, conforme aponta o gráfico 01.

Quadro 01: Fatores Críticos: Marketing

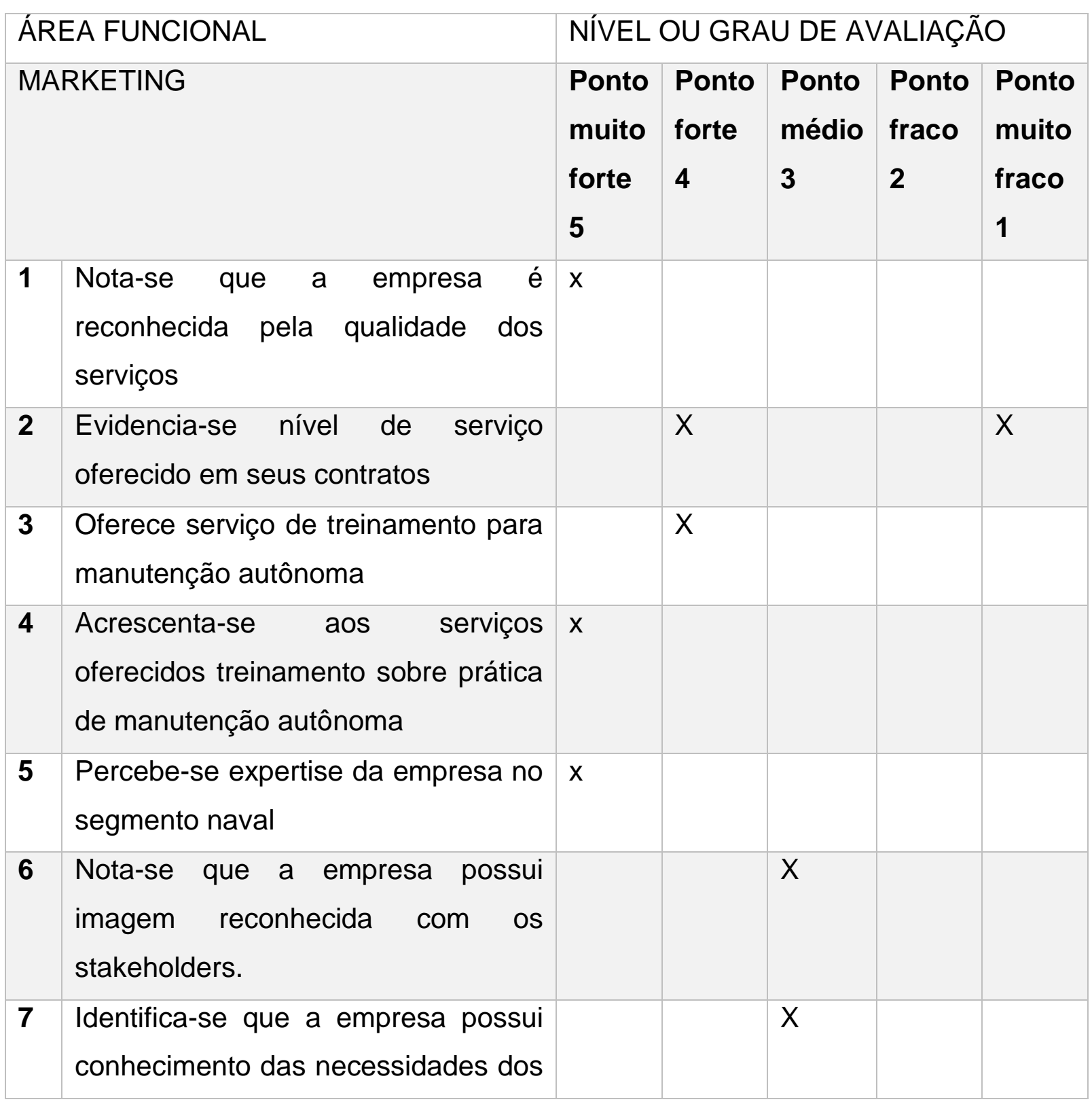

RC: 101765

Disponível em:

https://www.nucleodoconhecimento.com.br/administracao/implementacao-detreinamento 


\begin{tabular}{|l|l|l|l|l|l|}
\hline $\mathbf{8}$ & $\begin{array}{l}\text { clientes. } \\
\text { Destaca-se pela capacidade técnica } \\
\text { de seus colaboradores }\end{array}$ & & & & \\
\hline $\mathbf{9}$ & $\begin{array}{l}\text { Observa-se a construção de uma } \\
\text { marca sólida }\end{array}$ & & & & \\
\hline $\mathbf{1 0}$ & $\begin{array}{l}\text { Constata-se procedimentos } \\
\text { operacionais padronizados }\end{array}$ & & & & \\
\hline TOTAL $(\Sigma)$ & 15 & 8 & 6 & 2 & 2 \\
\hline MÉDIA POR GRAU (POR COLUNA) & 1,5 & 0,8 & 0,6 & 0,2 & 0,2 \\
\hline DESEMPENHO DA ÁREA $(\Sigma)$ TOTAL & 3,3 & & & \\
\hline
\end{tabular}

Fonte: Elaborado pelos autores, 2021.

De acordo com os fatores críticos apontados no quadro 01, pode-se destacar dois principais pontos negativos, que são: o nível do serviço oferecido e a construção de uma marca sólida. Ou seja, é de suma importância a observação e investimento da empresa referente a sua marca, sendo necessário uma intervenção para melhorias e alcance de novos clientes.

\subsection{PLANEJAMENTO DE AÇÕES}

Com a finalidade de progresso e avanço na empresa Netuno Engenharia Naval, desenvolveu-se um esquema para as ações que devem beneficiar a mesma, por meio de treinamentos e capacitações para os colaboradores, objetivando a melhoria no atendimento e serviços prestados.

Quadro 02 - Atividades Propostas

\begin{tabular}{|l|l|l|l|l|}
\hline & Ações Interventivas & Cronologia & Duração & Custo \\
\hline $\mathbf{0 1}$ & Fazer um mapeamento das atividades & 2 dias & 16 & $\mathrm{R} \$ 700,00$ \\
do departamento operacional & & horas. & Por \\
\hline
\end{tabular}

RC: 101765

Disponível em:

https://www.nucleodoconhecimento.com.br/administracao/implementacao-detreinamento 


\begin{tabular}{|c|c|c|c|c|}
\hline & & & & colaborador \\
\hline 02 & $\begin{array}{l}\text { Identificar a distribuição dessas } \\
\text { atividades entre os colaboradores }\end{array}$ & 2 dias & $\begin{array}{l}10 \\
\text { horas. }\end{array}$ & $\begin{array}{l}\mathrm{R} \$ 400,00 \\
\text { Por } \\
\text { colaborador }\end{array}$ \\
\hline 03 & $\begin{array}{l}\text { Organizar uma LNT para cada } \\
\text { colaborador dentro da organização }\end{array}$ & 5 dias & 20 horas & $\begin{array}{l}\mathrm{R} \$ 800,00 \\
\text { Por } \\
\text { colaborador }\end{array}$ \\
\hline 04 & $\begin{array}{l}\text { Treinamento voltado para Gestão do } \\
\text { Tempo e Produtividade }\end{array}$ & 30 dias & 60 horas & $\begin{array}{l}\mathrm{R} \$ 800,00 \\
\text { Por } \\
\text { colaborador }\end{array}$ \\
\hline 05 & $\begin{array}{l}\text { Avaliar a necessidade de contratação } \\
\text { de mão-de-obra. }\end{array}$ & $1 \mathrm{dia}$ & 5 horas & $\mathrm{R} \$ 300,00$ \\
\hline
\end{tabular}

Fonte: Elaborado pelos autores, 2021.

Os recursos propostos na tabela foram elaborados para aprimorar e aperfeiçoar o serviço prestado pela empresa, planejando um diferencial no mercado que se encontra cada vez mais competitivo.

\subsubsection{FAZER UM MAPEAMENTO DAS ATIVIDADES DO DEPARTAMENTO OPERACIONAL.}

Pontuou-se que o setor operacional é o que dá forma ao produto e serviço de uma organização. Dessa maneira, tem como finalidade garantir resultados positivos sobre o objeto da empresa.

Quadro 03 - Fazer um mapeamento das atividades do departamento operacional

\section{Fazer um mapeamento das atividades do departamento operacional}

O quê? Identificar melhorias no processo.

Por quê? Garantir o resultado positivo para a qualidade no processo da empresa. 
Onde? Na Organização.

Quando? Terceira semana de outubro de 2021.

Quem? Sócios, e os colaboradores da Netuno.

Como? Elaborando formulários que serão aplicados por um especialista.

Quanto? $R \$ 700,00$.

Fonte: Elaborado pelos autores, 2021.

Mediante análise do primeiro quadro, espera-se que com o mapeamento de processos sendo realizado de maneira correta, haja otimização das tarefas executadas e um aumento de rendimento, pois, a partir do mapeamento, o colaborador consegue compreender seu papel dentro da organização.

\subsubsection{IDENTIFICAR A DISTRIBUIÇÃO DESSAS ATIVIDADES ENTRE OS COLABORADORES.}

Percebeu-se que é necessário definir ações direcionadas ao alcance de metas, a fim de que a equipe esteja alinhada e tenha um bom desempenho, promovendo resultados positivos à empresa. Espera-se que cada funcionário possa compartilhar informações sobre suas atividades, visando melhorar cada tarefa às quais estão envolvidos.

Quadro 04 - Identificar a distribuição dessas atividades entre os colaboradores.

\section{Identificar a distribuição dessas atividades entre os colaboradores}

O quê? Planejar atividades, controlar e distribuir tarefas da equipe.

Por quê? Garante a qualidade dos serviços visando um ambiente produtivo.

Onde? No processo das atividades.

Quando? Dois de novembro de 2021.

Quem? Todos os colaboradores da Netuno.

Como? Estabelecer indicadores para avaliar a capacidade produtiva. 
Quanto? $\mathrm{R} \$ 400,00$.

Fonte: Elaborado pelos autores, 2021.

A verificação da distribuição dos serviços realizados por cada colaborador dentro organização é fundamental para que não ocorra o acúmulo de múltiplas tarefas por uma única pessoa. O objetivo desta ação é dividir responsabilidades e fazer com que os funcionários troquem ideias entre si, colaborando para o desenvolvimento de cada tarefa a ser realizada.

\subsubsection{ORGANIZAR UMA LNT PARA CADA COLABORADOR DENTRO DA ORGANIZAÇÃO.}

Identificou-se que é necessário corrigir erros e implantar melhorias nas rotinas de trabalho de cada colaborador, visando a qualidade do serviço oferecido pela organização. Assim, com a implementação da ferramenta de LNT, é possível trabalhar as habilidades potenciais de cada colaborador.

Quadro 05 - Organizar uma LNT para cada colaborador dentro da organização.

\section{Organizar uma LNT para cada colaborador dentro da organização.}

\begin{tabular}{|l|l|}
\hline O quê? & Medir a produtividade dos colaboradores. \\
\hline Por quê? & Saber quais os pontos a melhorar na sua equipe. \\
\hline Onde? & Empresa Netuno. \\
\hline Quando? & Segunda semana de novembro. \\
\hline Quem? & Funcionários da Organização. \\
\hline Como? & Através de questionário dado em formato de ficha. \\
\hline Quanto? & $\mathrm{R} \$ 800,00$ \\
\hline
\end{tabular}

Fonte: Elaborado pelos autores, 2021. 
Com a execução desta ação, almeja-se definir quais são as necessidades de cada colaborador mediante a execução de suas tarefas, e identificar possíveis falhas nos processos, para posteriormente impulsionar as soluções necessárias para alcançar suas metas.

\subsubsection{TREINAMENTO VOLTADO PARA GESTÃO DO TEMPO E PRODUTIVIDADE.}

Apresenta-se neste tópico, os aspectos que fazem da estratégica, assim como a utilização da lista de ocupações e a organização no trabalho. Uma simples agenda de tarefas pode trazer hábitos de uma boa relação com o tempo. Identifica-se que pessoas que apresentam produtividade para com a organização tendem a alcançar níveis mais elevados.

Quadro 06 - Treinamento voltado para Gestão do Tempo e Produtividade.

\section{Treinamento voltado para Gestão do Tempo e Produtividade. \\ O quê? Melhorar a Gestão de tempo e obter bons resultados. \\ Por quê? Proporcionar conhecimento aos colaboradores. \\ Onde? Na organização. \\ Quando? Terceira semana de novembro de 2021. \\ Quem? Todos os colaboradores da Netuno. \\ Como? Aplicando ferramentas de Gestão de tempo. \\ Quanto? $\mathrm{R} \$ 800,00$}

Fonte: Elaborado pelos autores, 2021.

Espera-se que ao colocar em prática esta ação, os colaboradores possam obter a capacidade de priorizar e agendar atividades, segundo grau de importância, e gerir bem os afazeres, determinando horários com o intuito de evitar tempo desperdiçado. 


\subsubsection{AVALIAR A NECESSIDADE DE CONTRATAÇÃO DE MÃO-DE- OBRA.}

Decidir contratar ou não um novo colaborador exige planejamento. Isto é, o empregador deve agir de forma cautelosa, visando a qualidade de entrega da mão de obra e se o novo colaborador coadjuvará com o crescimento da organização.

Quadro 07 - Avaliar a necessidade de contratação de mão-de-obra.

\section{Avaliar a necessidade de contratação de mão-de-obra.}

O quê? Contratação de um Assistente Administrativo.

Por quê? Para melhorar a interação com os clientes.

Onde? Empresa Netuno.

Quando? Primeira semana de outubro.

Quem? A empresa.

Como? Contratando um assistente administrativo com os direitos propostos na CTL.

Quanto? R $\$ 300,00$

Fonte: Elaborado pelos autores, 2021.

Por fim, faz-se necessário avaliar a contratação de mão-de-obra, verificando os custos e se realmente há essa necessidade. $O$ objetivo é fazer com que os atrasos e a demora nos serviços sejam resolvidos. Assim, se mesmo após as ações acima a demanda estiver maior do que a quantidade de funcionários para atender, é importante esta nova contratação.

\section{CONSIDERAÇÕES FINAIS}

Diante das ideias abordadas e do estudo realizado na empresa Netuno Engenharia Naval, constatou-se que a inexistência de um programa de treinamento e capacitação para os colaboradores pode acarretar resultados negativos para a

RC: 101765

Disponível em:

https:/www.nucleodoconhecimento.com.br/administracao/implementacao-detreinamento 
organização e causar a insatisfação de seus clientes mediante os serviços oferecidos.

Levando em consideração esses aspectos, o estudo de caso teve como objetivo principal diagnosticar o fator problema dentro da empresa, para propor ações interventivas, com a finalidade de estabelecer um programa de capacitação de mão de obra, na intenção de obter o crescimento da organização por meio da qualidade do atendimento do nível de serviço.

Nesse contexto, ao retomar os objetivos específicos, estabelecidos no início do trabalho, a presente pesquisa possibilitou identificar os problemas nos processos de atendimento, por meio de um mapeamento de serviço dos setores, e avaliou diferentes tipos de treinamento, possibilitando a aplicação de estratégias por meio do levantamento de necessidades de treinamento e a utilização da ferramenta $5 \mathrm{~W} 2 \mathrm{H}$.

Acredita-se que foram acrescentadas melhorias no nível de serviços oferecido pela empresa, consolidando a marca e desenvolvendo a capacidade intelectual de seus funcionários. A pergunta problema apresentada foi: como a estruturação de um programa de capacitação de mão de obra pode subsidiar o crescimento da organização por meio da qualidade do atendimento do nível de serviço?

Portanto, mediante os dados observados, conclui-se que o trabalho proporcionou a solução da questão norteadora da pesquisa, através do processo de criação de ações interventivas que pretendem resolver o problema, porém as ações sugeridas devem ser executadas de forma correta. Do ponto de vista estratégico, o trabalho foi concluído e os sócios da empresa Netuno Engenharia Naval compreenderam a importância de um programa de treinamento e desenvolvimento, tendo em vista que, colaboradores motivados e qualificados desempenham um bom rendimento, resultando na expansão e crescimento da empresa. 


\section{REFERÊNCIAS}

ARAGÃO, J. W. M. de.; NETA, M. A. H. M. Metodologia Científica. Salvador: UFBA, Faculdade de Educação, Superintendência de Educação a Distância, 2017.

COOPER, D. R.; SCHINDLER, P. S. Métodos de Pesquisa em Administração. 12a ed. Porto Alegre: AMGH Editora Ltda, 2016.

CORTELLA, M. S. Por que fazemos o que fazemos?. 1a ed. São Paulo: Editora Planeta, 2016.

DESSLER, G. Administração de recursos humanos. 4. Ed. São Paulo: Pearson Education do Brasil, 2014.

FRANCISCHINI, A. S. N.; FRANCISCHINI, P. G. Indicadores de Desempenho: dos objetivos à ação - métodos para elaborar KPIs e obter resultados. Rio de Janeiro: Alta Books, 2017.

KHOURY, K. É hora do show: técnicas para elevar seus treinamentos a outro patamar. São Paulo: DVS Editora, 2015.

LANGHI, C. Treinamento e Desenvolvimento: Acompanhamento e movimentação de pessoas. São Paulo: Editora SENAC São Paulo, 2019.

LIMA, P. G. PEREIRA, M. C. Pesquisa Científica em Ciências Humanas: Uma introdução aos fundamentos e eixos procedimentais. $1^{\underline{a}}$ ed. Uberlândia: Navegando Publicações, 2018.

MADRUGA, R. Treinamento e desenvolvimento com foco em educação corporativa. $1^{\underline{a}}$ ed. São Paulo: Saraiva Educação, 2018.

MARRAS, J. P. Avaliação de desempenho Humano. São Paulo: Elsevier Editora Ltda. 2012.

RC: 101765

Disponível em:

https://www.nucleodoconhecimento.com.br/administracao/implementacao-de-

treinamento 
MENEZES, A. H. N. et. al. Metodologia científica: teoria e aplicação na educação a distância. Petrolina-PE: Universidade Federal do Vale do São Francisco, 2019.

NOE, R. A. Treinamento e desenvolvimento de pessoas: teoria e prática. $6^{\mathrm{a}} \mathrm{ed}$. Porto Alegre: AMGH, 2015.

PAES, K. D. Gestão de Pessoas. Natal: Edunp, 2011.

PARADELA, V. C.; GOMES, A. P. C. Z. Aprendizagem e desenvolvimento de talentos. Rio de Janeiro: FGV Editora, 2021.

PEREIRA, A. S. et al. Metodologia da Pesquisa Científica. $1^{\text {a }}$ ed. Santa Maria, RS: UFSM, NTE, 2018.

REICHEL, H. Treinamento e desenvolvimento. Curitiba: IESDE Brasil S.A. 2008.

RIBEIRO, A. Gestão de treinamento de pessoas. 1.ed. São Paulo: Saraiva Educação, 2018.

SANTOS, S. R. dos; LOPEZ, R. de P. Manual de treinamento e desenvolvimento: uma abordagem técnica e pedagógica. $1^{\text {a }}$ ed. Porto Alegre: Simplíssimo, 2021.

TONET, H. C. et al. Liderança e gestão de pessoas em ambientes competitivos. Rio de Janeiro: Editora FGV, 2012.

YIN, R. K. Estudo de Caso, planejamento e métodos. 5 $5^{\text {a }}$ ed. Porto Alegre: Bookman, 2015.

ZAMBELlO, A. V. et. al. Metodologia da Pesquisa e do Trabalho Científico. $1^{\text {a }}$ ed. São Paulo: FUNEPE, 2018.

ZANELLA, L. C. H. Metodologia de Pesquisa. $2^{\underline{a}}$ ed. Florianópolis: Departamento de ciências da administração/UFSC, 2013. 
Enviado: Outubro, 2021.

Aprovado: Novembro, 2021.

RC: 101765

Disponível em:

https://www.nucleodoconhecimento.com.br/administracao/implementacao-detreinamento 